\title{
THE EFFECTS OF ORGANIZATIONAL CLIMATE ON THE PRIVET INSTITUTIONS IN THE SULTANATE OF OMAN: A THEORETICAL FOUNDATIONS STUDY

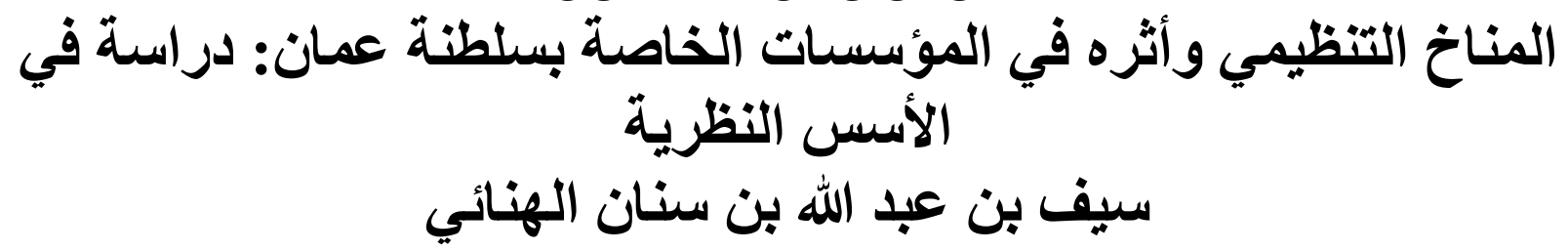

\author{
Al Hinaai Saif Abdallah Sinan ${ }^{1 *}$, Abd Whhab Bin Zakrya ${ }^{2} \&$ \\ Mohd Burhan Ibrahim ${ }^{3}$ \\ ${ }^{1}$ Ph.D. Candidate, Faculty of Education, International Islamic University Malaysia (IIUM): \\ ssinaan@soharuni.edu.om \\ ${ }^{2}$ Prof. Dr., Kulliyyah of Education, International Islamic University Malaysia (IIUM): \\ abd.wahab@iium.edu.my \\ ${ }^{3}$ Prof. Dr., Kulliyyah of Education, International Islamic University Malaysia (IIUM) \\ mburhan@iium.edu.my \\ ${ }^{*}$ Corresponding Author
}

\begin{abstract}
This article discusses the theoretical foundations of the organizational climate. It is part of a field study conducted by the researcher in the private institutions of the Sultanate of Oman. The problem is that the organizations' lack of awareness of the importance of the prevailing organizational climate in them, and reviewing it from time to time despite the close link between it and organizational development, stimulating the creative behavior of workers and the motivations of workers and raising their level of morale and improving the level of their performance; has formed a problem that deserves attention and research. Therefore, the objectives of the study are: to identify the characteristics and significance of the organizational climate; diagnosing the types of organizational climate and the factors affecting it. To present organizational climate models. The descriptive method was used to identify the characteristics, significance, types and models of the organizational climate. The findings of the study indicated: that the organizational climate is a mediator between job requirements and the needs of the individual and that job satisfaction is part of the organizational climate. The importance of the organizational climate to produce and demonstrate the organization's ability to achieve its goals is demonstrated. The control and control to properly direct the elements of the organizational climate enable the organization's management to motivate individuals and push them towards hard work. There are several factors that affect the organizational climate: material and economic resources, specific administrative policies for selection, promotions, and wages, professional values for administrators and employees, flexible and open organizational structures.
\end{abstract}

Keywords: organizational climate, characteristics, types, and influencing factors. 


\section{الملخص}

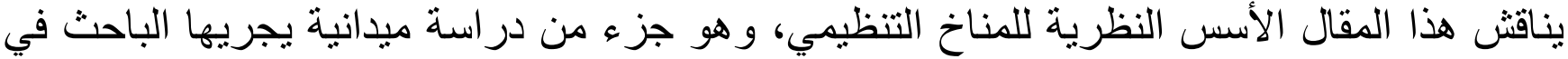

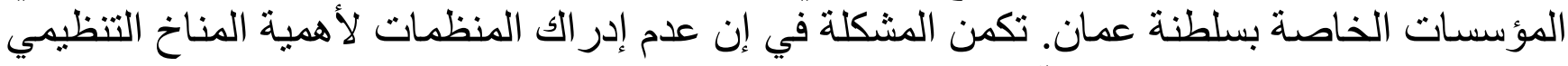

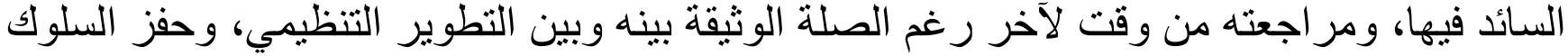

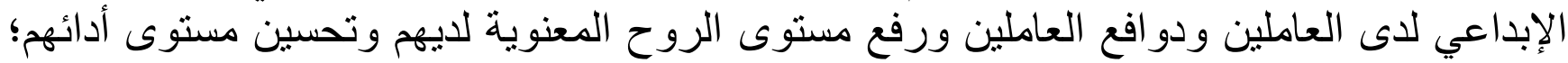

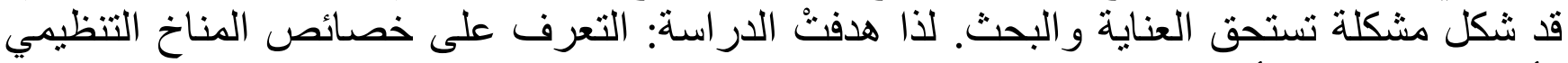

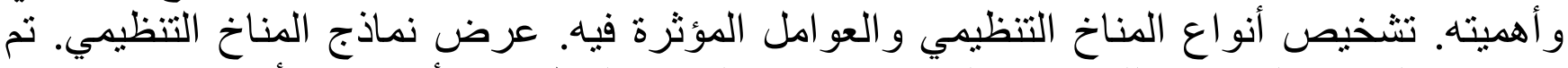

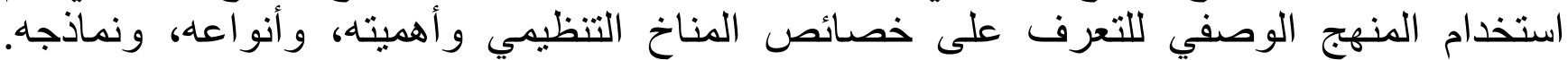

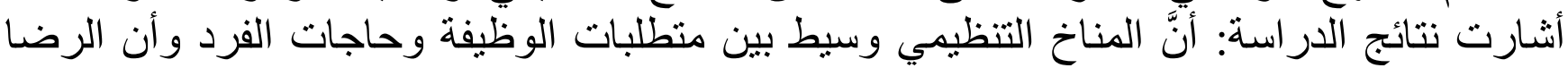

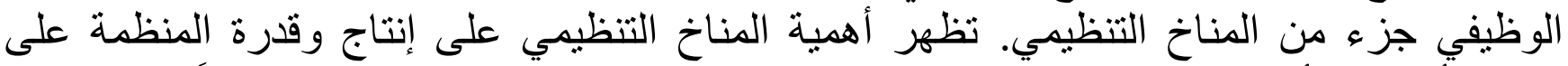

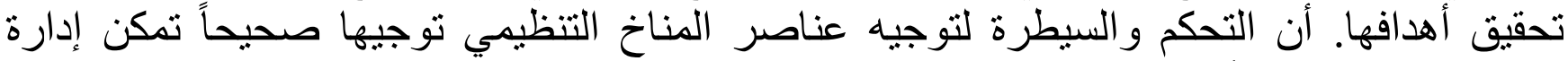

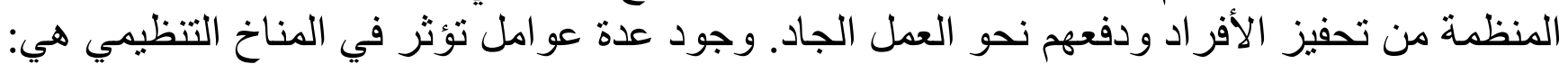

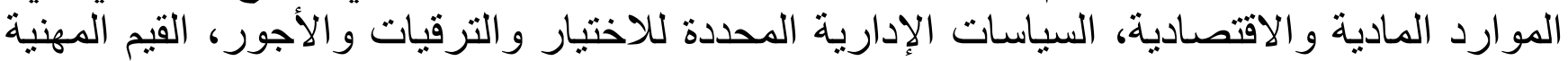

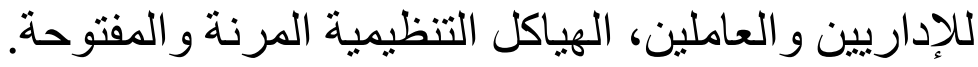

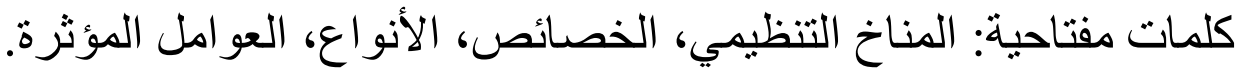

\section{المقدمة}

لقد أخذت فكرة المناخ التنظيمي طريقها إلى الظهور مع مطلع الستينات من القرن الماضي، ومنذ ذلك الحين و هي تمضي باهتمام العديد من الباحثين، خاصة في ميدان التنظيم و السلوك التنظيمي (الثربيني

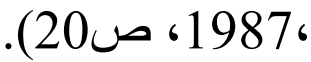

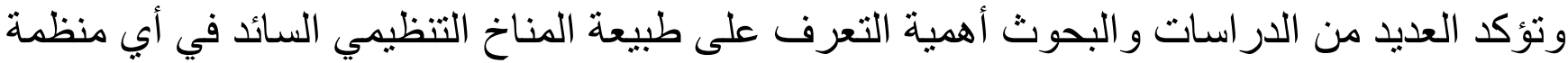

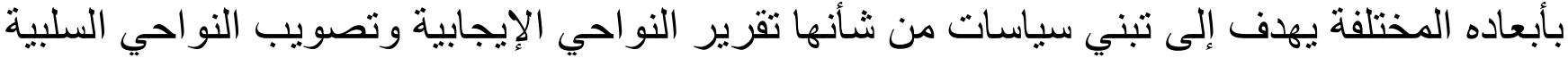

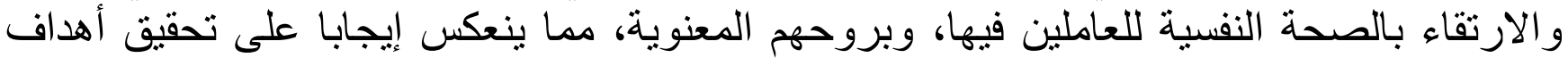

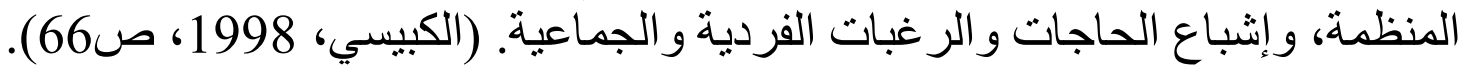
لذا يجب أن تكون المؤسسات حريصة على انتقاء كوادر ها الوظيفية وأن تسعى جاهدة إلى تنمية

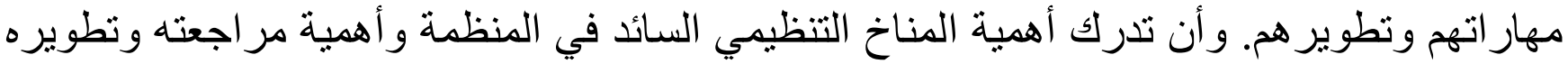

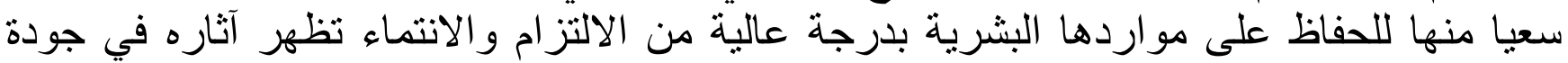
أدائهر. لإنجاز العمل بكفاءة عالية.

مفهوم المناخ التنظيمي ويمثل المناخ التنظيمي بيئة العمل الداخلية بمختلف متغير اتها وخصائصها وتفاعلاتها، حيث يلعب 
المناخ التنظيمي دور ا كبير ا في ترصين السلولك الأخلاقي و الوظيفي للأفر اد العاملين من ناحية تشكيل

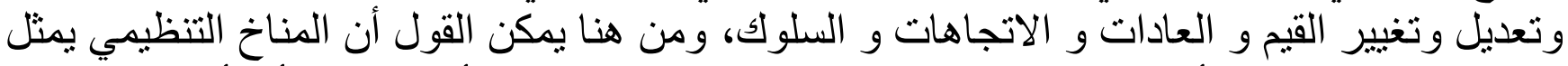

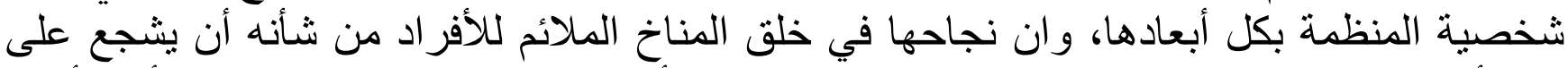

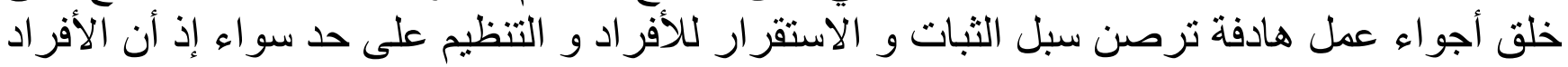

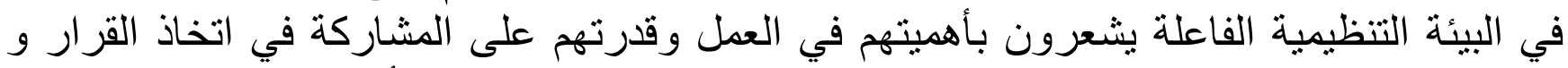
الإسهام في رسم السياسات و الخطط ويسود شعور بالثقة بين الإدارة و الأفراد (عوض في الثة ، 2013، . (136-135

هذا ويتصف المناخ التنظيمي بثلاثة خصائص رئيسية تتمثل في: العدالة Fairness وهي نثير إلى

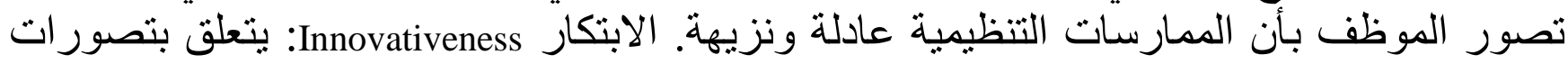

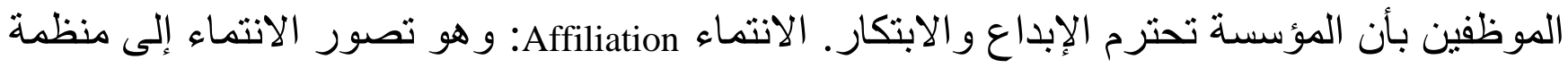
(Al-Kurdi et al. , 2020, 219)

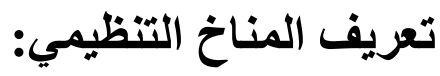

أما عن تعريف المناخ التنظيمي، فيعرف على أنه مجمو عة من الخصائص التي تصف المنظمة ونؤثر على سلوك الموظفين (Dargahiet al. , 2013, 32). كذلك يعرف المناخ التنظيمي على أنه نتيجة للتفاعل بين هيكل المنظمة وأنظمتها وثقافتها وسلوكها

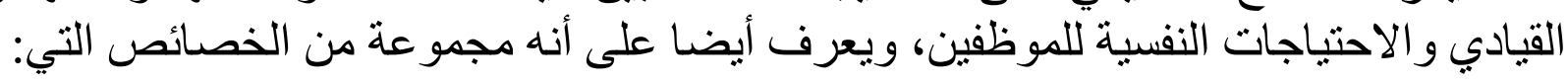
(أ) تصف المنظمة وتميز ها عن المنظمات الأخرى (ب) دائمة نسبيًا بمرور الوقت (ج) تؤثر على سلوك الأشخاص في في المنظمة. أي إنها بنية معيارية للمواقف والمتئي لايير السلوكية، توفر الأساس لتفسير المواقف وتكون بمثابة مصدر

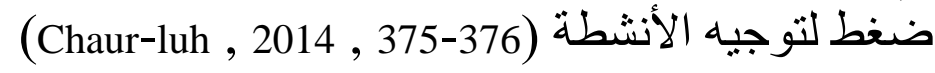

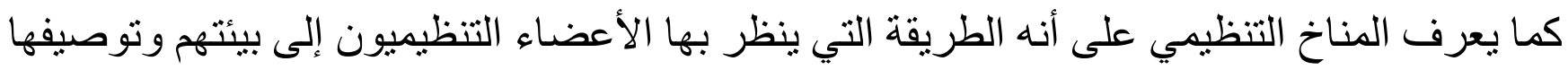

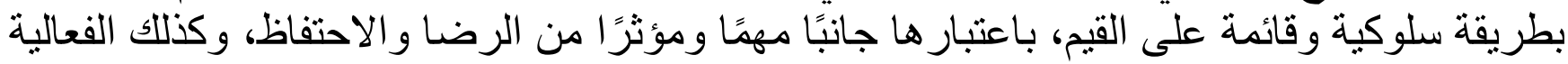
المؤسسية (Gudeta , 2018 ( 2)

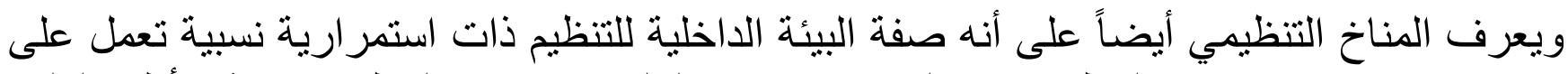

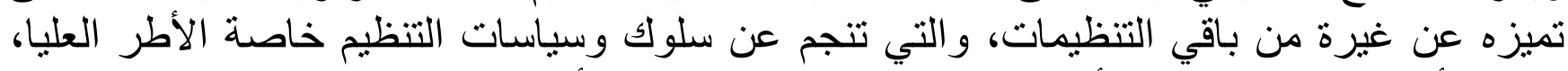

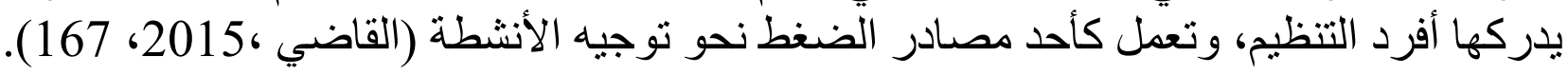
يتضح مما سبق إن المناخ التظظيمي هو محصلة الممارسات والعمليات و والعلاقات القائمة داخل

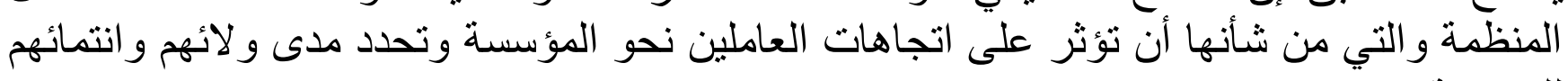
للمؤسسة. مشكلة الدراسة: 
في إطار حرص المؤسسات على انتقاء كو ادرها الوظيفية والمحافظة عليها؛ يجب أن تدرك أهمية

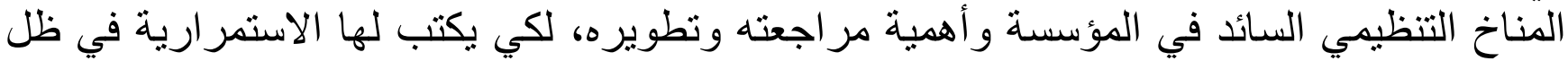

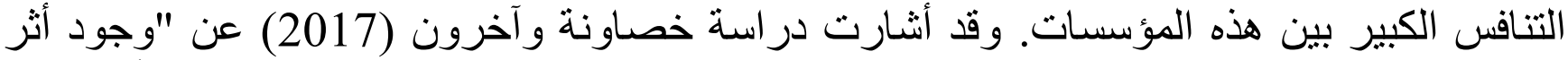

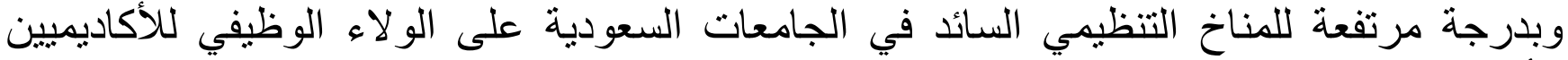

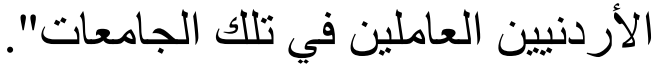

أما محمود (2013) فقد أظهرت نتائج بحثه "وجود علاقة إيجابية قوية بين عناصر المائ المناخ التنظيمي

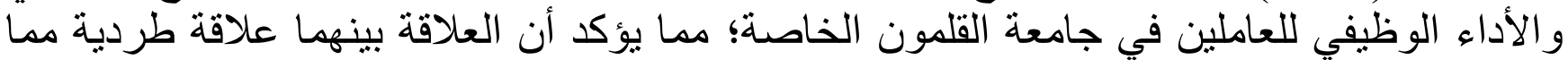

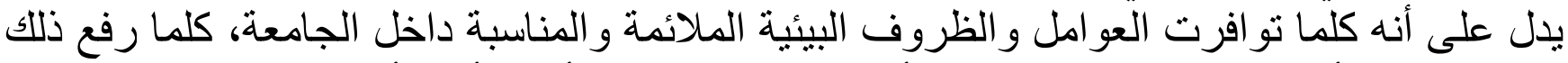

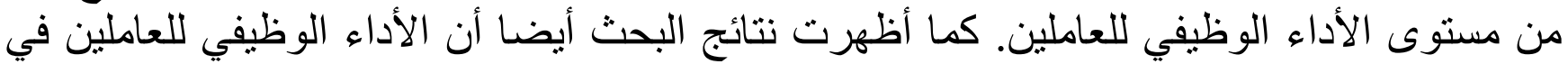

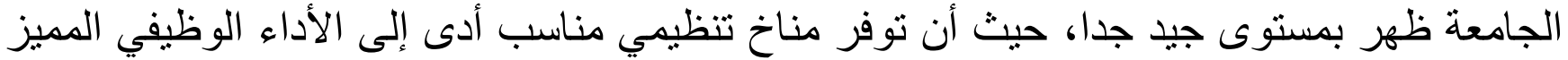

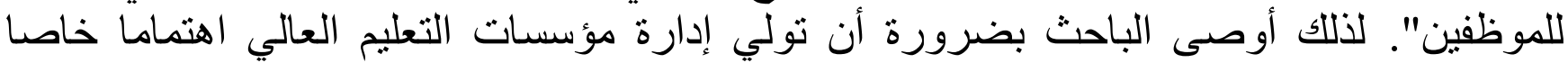

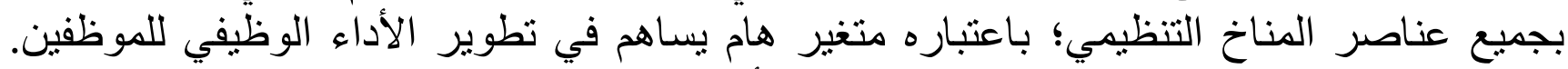

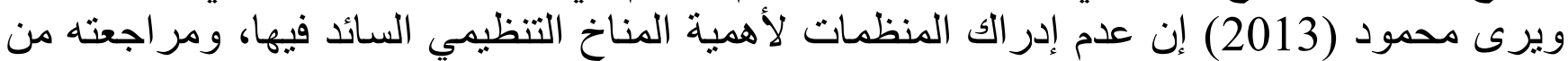

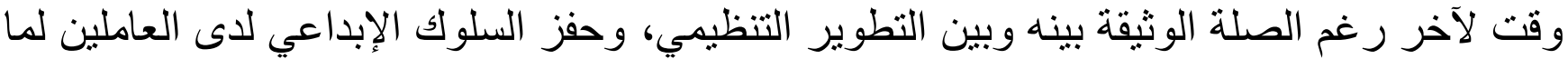

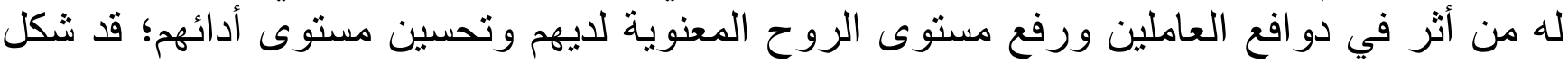
مشكلة تستحق العناية و البحث.

ومن خلال ما سبق فإن الباحث سيوضح أهمية وابعاد المناخ التنظيمي سعيا لتحفيز المؤسسات

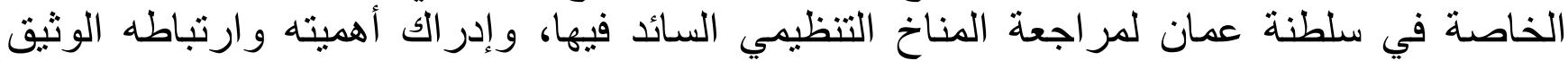

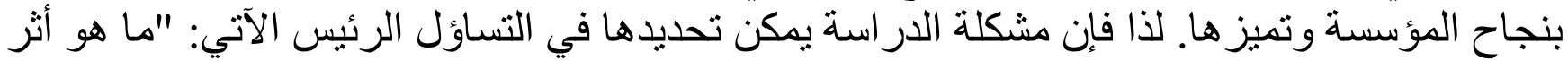
المناخ التنظيمي على المؤسسات الخاصة بسلة بسلطنة عمان.

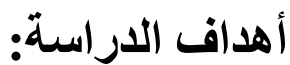
أ. التعرف على خصائص المناخ التنظيمي و أهميته. ب. تشخيص أنواع المناخ التنظيمي و العو امل المؤثرة فيه. ت. ت عرض نماذج المناخ التنظيمي.

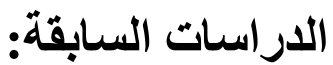
دراسة محمد (2016): المناخ التظيمي وعلاقته بالتطوير التظيمي: دراسة ميدانية على العاملين الإداريين بجامعة تبوك.

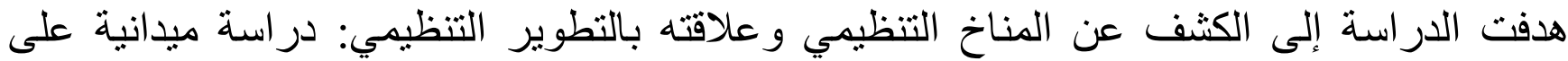

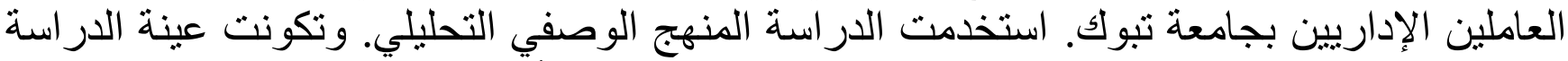

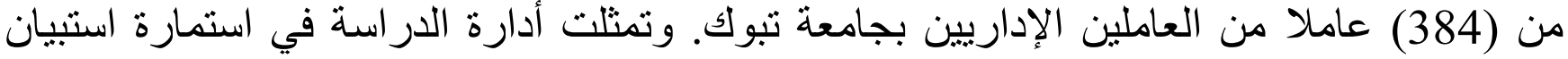

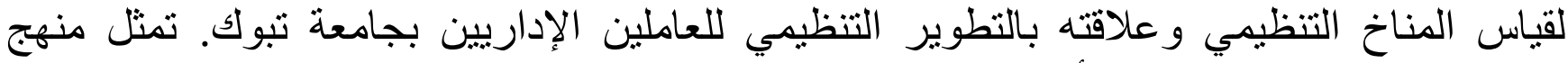
الدر اسة في المنهج الارتباطي. أثنارت نتائج الدر اسة إلى وجود علاقة ذات دلالة إحصائية بين عنصر 
الهيكل التظيمي و التطوير التنظيمي على مستوى الأفر اد، مما يدل على أن العلاقة دالة إحصائياً بينهم

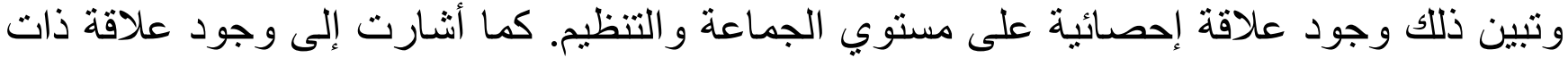

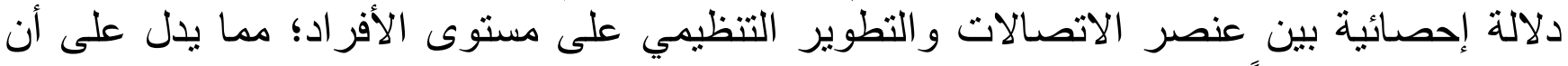
العلاقة دالة إحصائياً بينهم.

دراسة العصيمي (2016): واقع المناخ التنظيمي في جامعة الطائف من وجهة نظر أعضاء هيئة التدريس.

هدفت الدر اسة إلى التعرف على و اقع المناخ التنظيمي في جامعة الطائف من وجهة نظر أعضاء هيئة التهاء

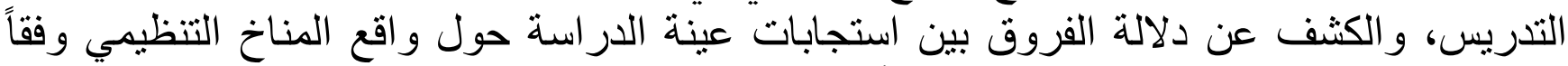

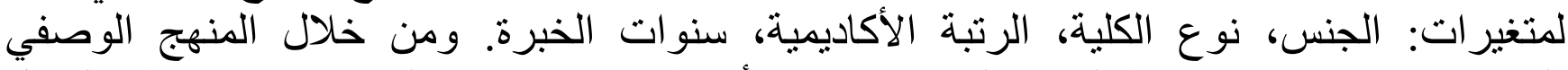

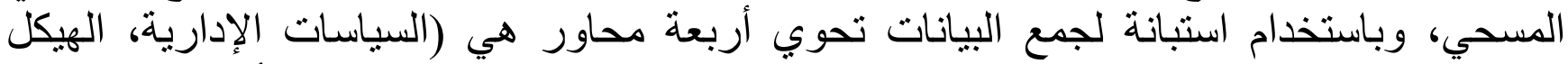

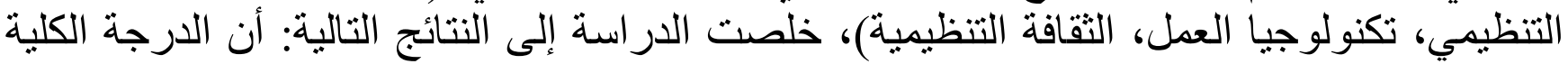

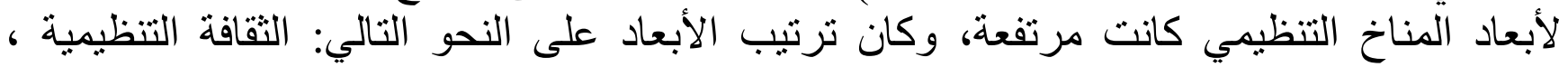

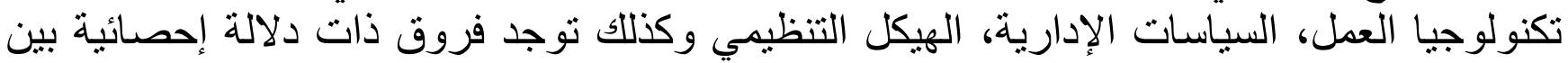

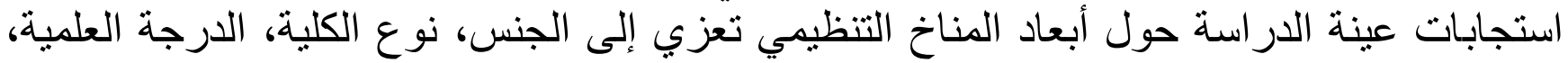

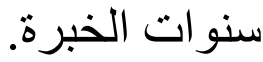
دراسة خصاونة وآخرون (2017): مستوى الرضا لدى الأكاديميين الأردنيين العاملين في الجامعات

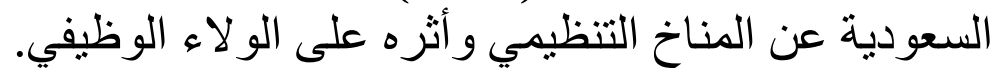

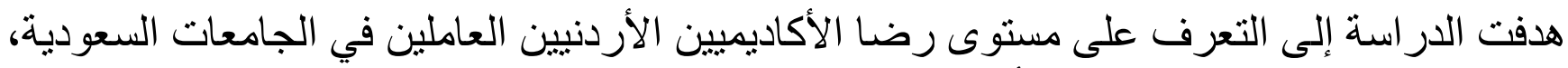

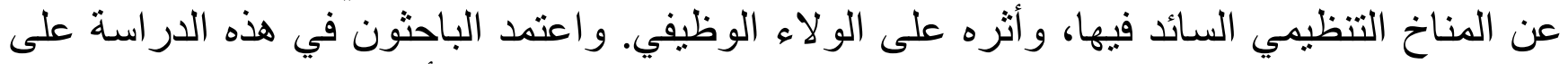

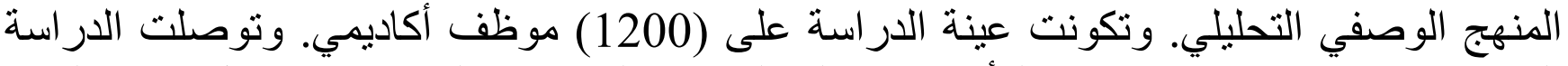

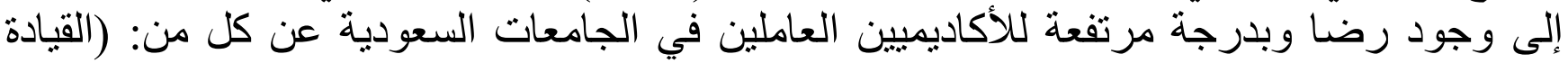

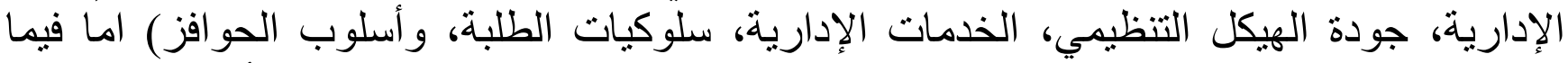

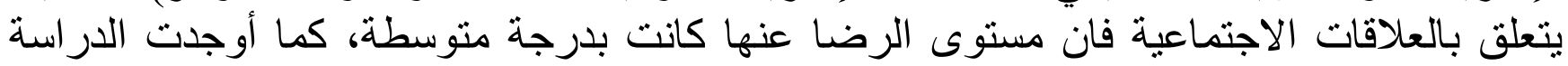

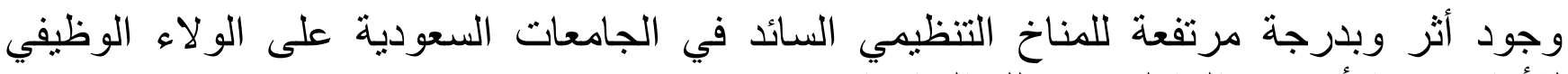
للأكاديميين الأردنيين العاملين في تلألك الجامعات. دراسة العبادي وبطاح (2017): المناخ التنظيمي السائد في الجامعات الأردنية الرسمية و الخاصة لإقليم الوسط من وجهة نظر أعضاء العضاء الهيئة التدريسية.

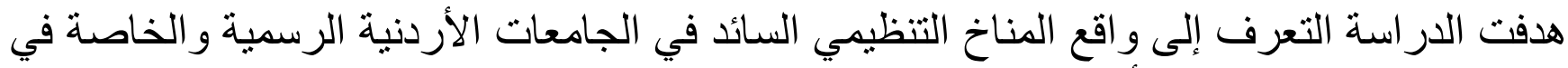

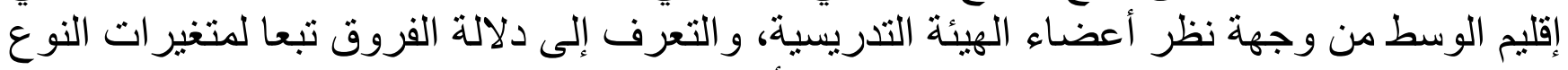

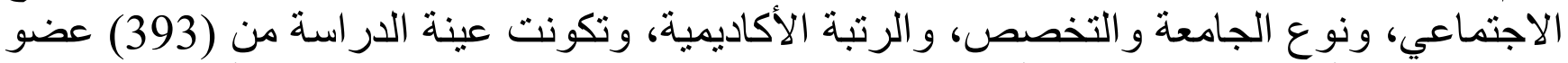

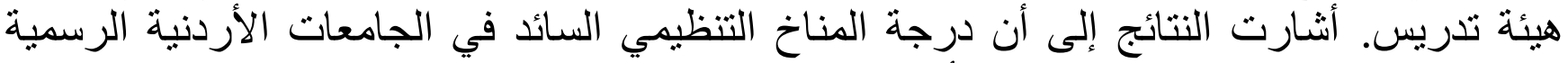

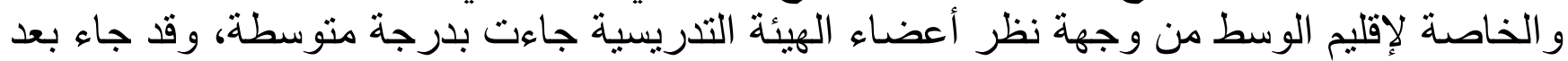
(العلاقات و الاتصالات) في المرتبة الأولي وبدرجة مرتفعة، في حين جاء بعد (السلوك القية القيادي) في 
المرتبة الأخيرة وبدرجة منوسطة. أثنارت النتائج إلى عدم وجود فروق ذات دلالة إحصائية في درجة

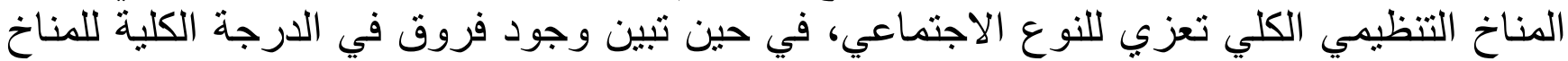

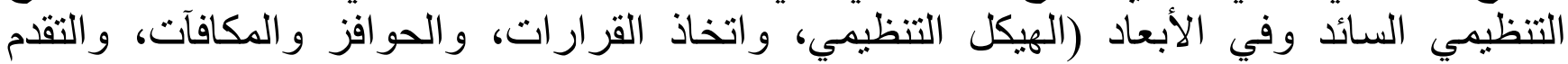

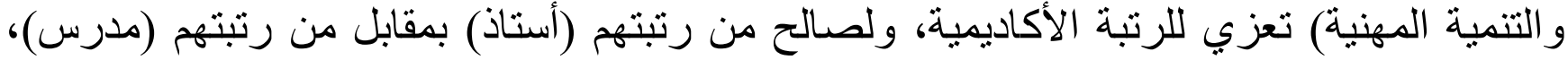

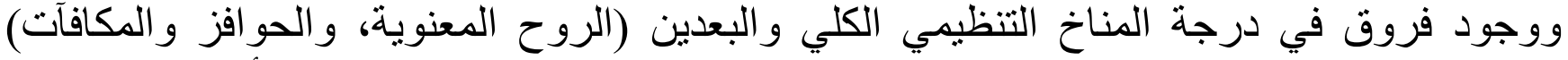

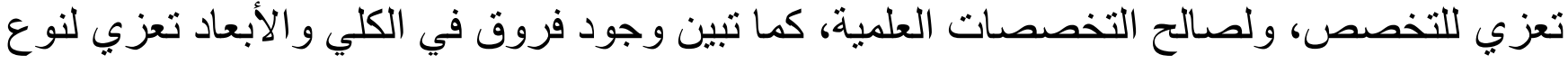
الجامعة، ولصالح الجامعات الرسمية.

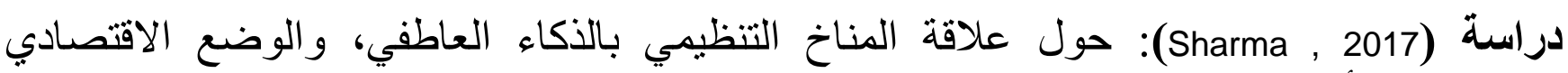

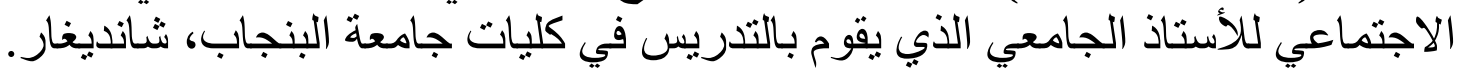

The relations of Organizational climate with emotional Intelligence and socioeconomic status teacher educator teach in affiliated colleges of Panjab University, Chandigarh.

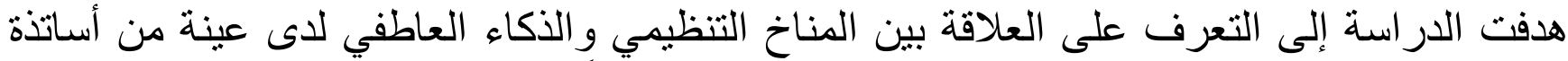

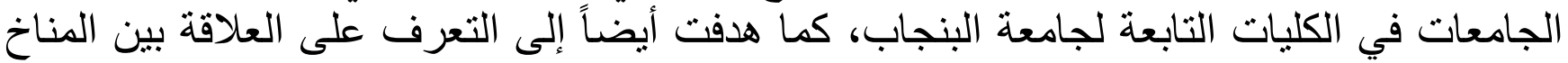

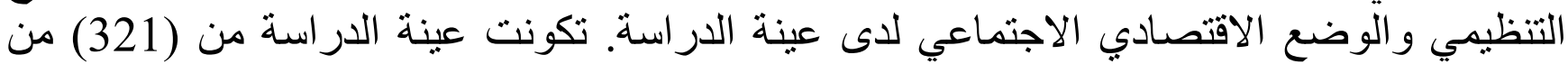

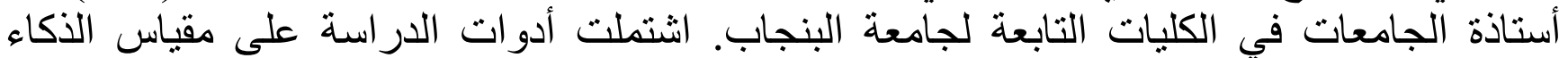

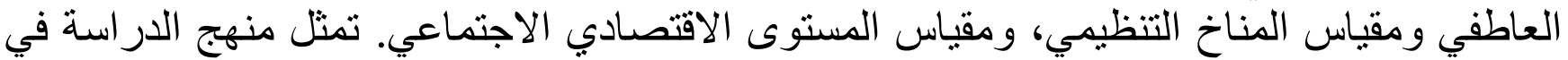

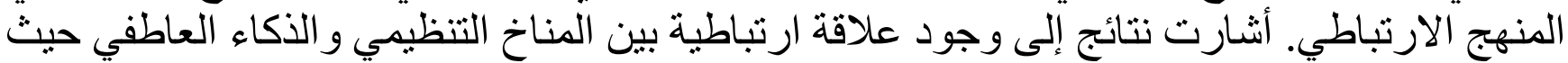

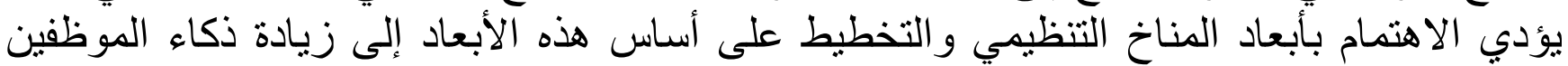

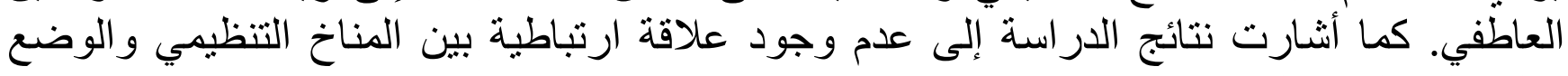
الاقتصادي الاجتماعي.

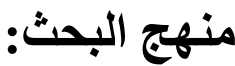

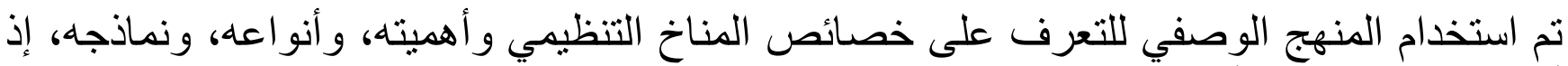
أن البحوث الوصفية أكثر طرق البحث شيو عا؛ بسبب حصولها على حقائق دقيقة عن الظروف القائية القائهة

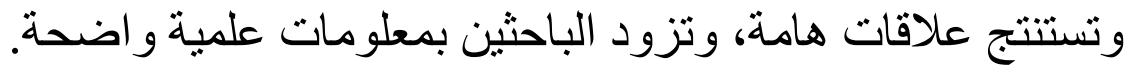
وتناقش هذه المقالة الموضوع وفق المباحث الآتية: المبحث الأول: خصائص المناخ التنظيمي و أهميته. المبحث الثاني: أنواع المناخ التنظيمي و العو امل المؤثرة فيه. المبحث الثالث: نماذج المناخ التنظيمي. المبحث الأول: خصائص المناخ التنظيمي وأهميته المطلب الأول: خصائص المناخ التنظيمي تتمثل خصائص المناخ التنظيمي في النقاط الآتية: 
ـ تأثير المناخ التنظيمي الواضح على العاملين في المؤسسة سلباً أو إيجاباً؛ لأنه وسيط بين متطلبات الوظيفة وحاجات الفرد، وليس بأية حال هو الرضا الوطي الوظيفي، لأن هذا الأخير هو جزء الونه من المناخ التنظيمي.

- يعكس المناخ التنظيمي التفاعل بين المميزات الثخصية والتنظيمية، ويعبر عن خصائص المنظمة، كما يتم إدر اكها من قبل العاملين في هذه المنظمة.

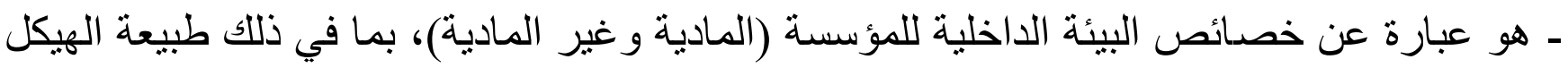
التظيمي، نمط القيادة، نمط الاتصالات، المشاركة في اتخاذ القرار ات، طبيعة العمل، التكنولو جيا. - يختلف المناخ التنظيمي عن المناخ الإداري، فبينما يعد المناخ التنظيمي أحد المحددات الأساسية

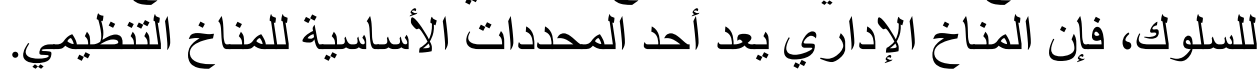

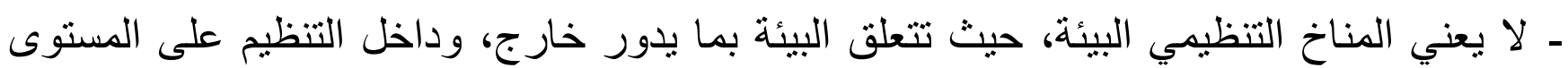

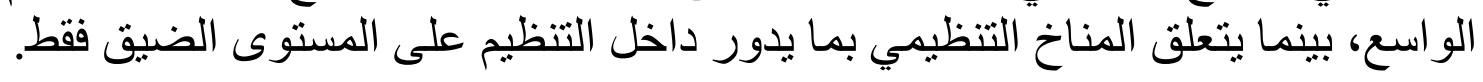

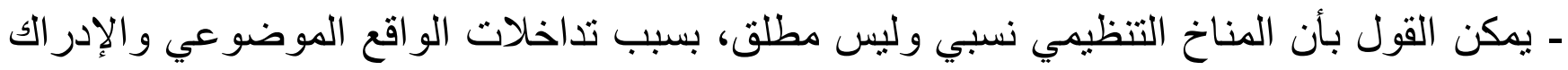

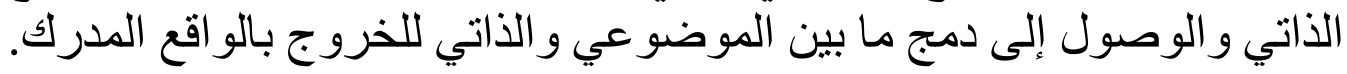
كما بتسم المناخ التظظيمي بمجمو عة من الخصائص يذكر ها على النحو الآتي:

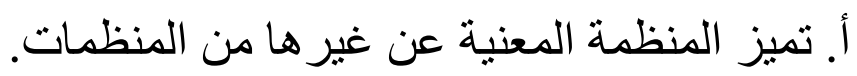

ب. ب. إن المناخ التنظيمي يمتاز بنوعية ثابتة: بمعنى أن خصائص المناخ التنظيمي تتسم بدرجة من الاستمرار النسبي.

ت. المناخ فكرة من نسيج واحد لا تتجز أ مثل الثخصية الإنسانية. ث. المناخ تجسيم معين لمتغير ات موضو عية.

ج. العناصر المكونة للمناخ قد تختلف ولكن تبقى هويته كما هو دائماً (فليه و عبد المجيد،

.) (195، 2005

\section{المطلب الثاني: أهمية المناخ التنظيمي}

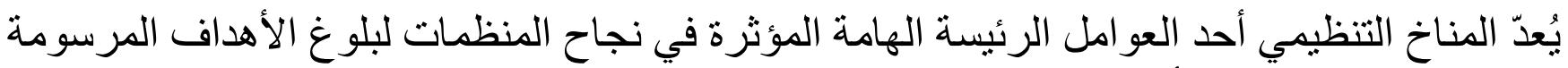

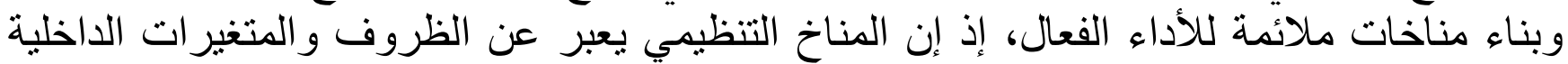

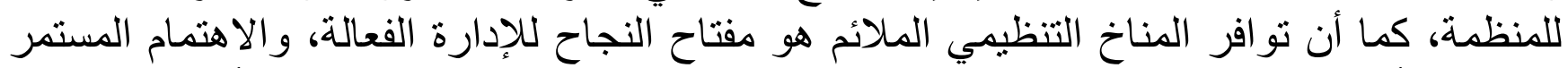

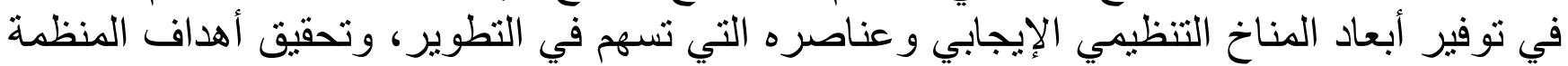

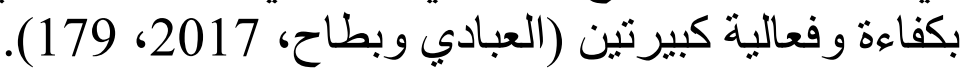

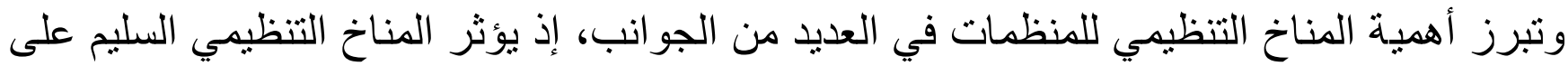

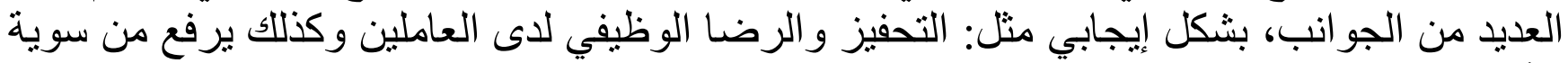
الأداء في المنظمة. كما يؤثر المناخ التظيمي على الجوانب النفية والنية الاجتماعية للعاملين داخل 
المنظمة بشكل إيجابي إذا كان المناخ التنظيمي سليم وصحي. بالإضافة إلى تأثثره على سلوك وكفاءة

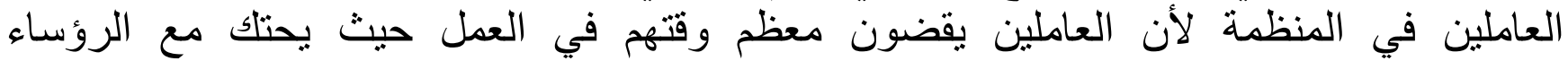
و المرؤوسين على كافة المسنويات، ويخضع في سلوكه لتأثيرات المناخ التنظيمي بأبعاده المختلفة

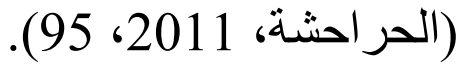

وبالإضافة إلى ما سبق، تظهر أهمية المناخ التنظيمي من خلال:

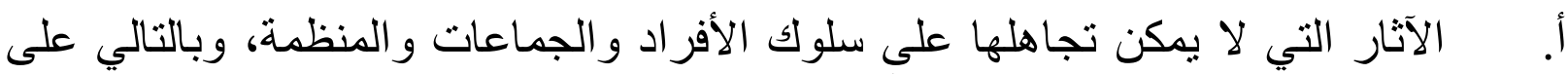
إنتاجهم و على قدرة المنظمة على تحقيق أهدافها.

ب. التأثثر على المنظمات في تحقيق أهدافها المخططة والتي قد ترتبط بالمناخ السائد داخل

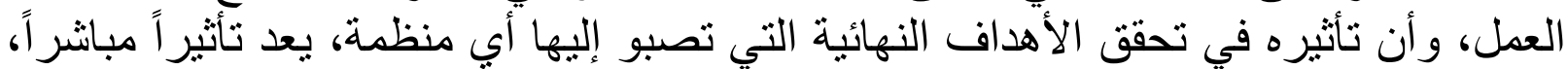

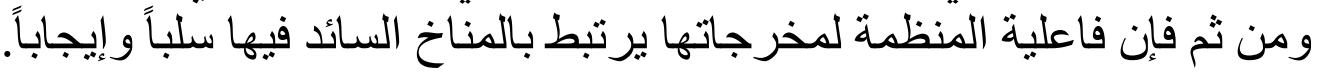

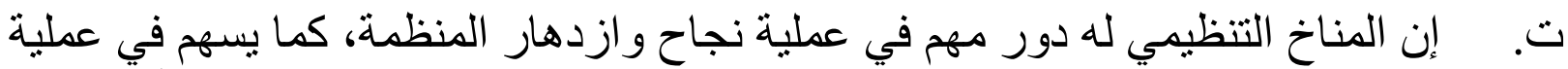

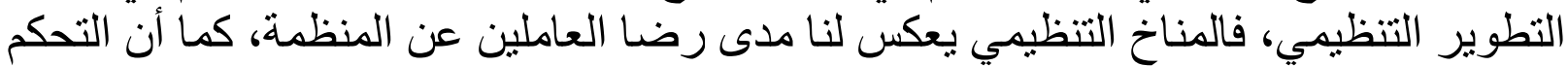
والسيطرة لتوجيه عناصر المناخ التنظيمي توجيها صحيحاً تمكن إدارة المنظمة من فن تحفيز

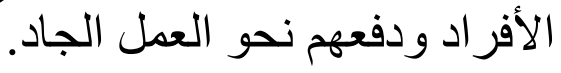

ث. تأثثره على الجوانب النفسية و الاجتماعية للعاملين داخل المنظمة.

ج. العلاقة التي تربطه بالمتغيرات التنظيمية فهو يؤثر بشكل مباثر في عملية التطوير

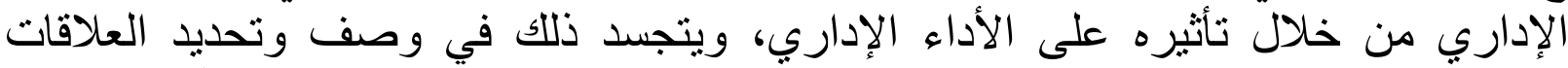

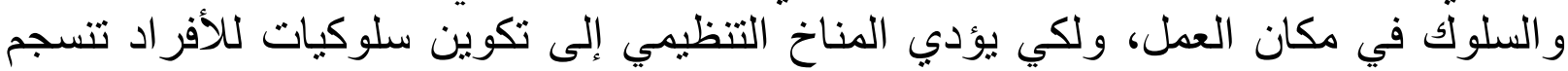
والتوقعات، فلا بد من أن تتوفر الملائمة بين المهار ات وقابلية الفيلية الفرد من جهة وبين متطلبات

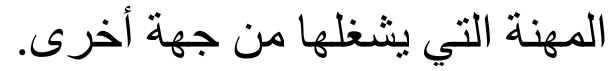

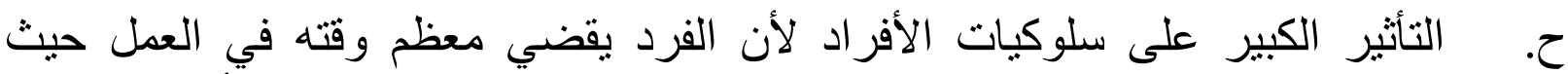

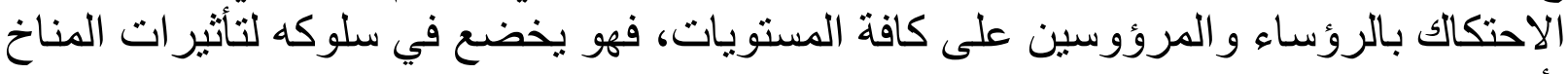
بأبعاده المختلفة.

خ. تأثيره على كفاءة العاملين داخل المنظمة، لأن قدرة المنظمة على تأدية المهام المناطة

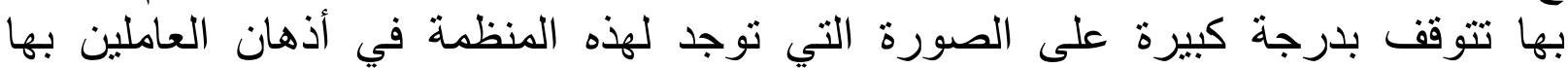

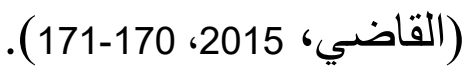

المبحث الثاني: أنواع المناخ التظظيمي والعوامل المؤثرة فيه المطلب الأول: أنواع المناخ التظظيمي هنالك ستة أنواع للمناخ التنظيمي هم: ـ المناخ المفتوح: هو تعبير عن المنظمات النشطة والحيوية التي تحاول الوصول إلى أهدافها وضمان رضا أعضاء المجموعة المعاء. 
ـ مناخ الحكم الذاتي: هو نوع المناخ الذي يكون فيه الزعيم منفصلًا تمامًا عن المجموعة ولديه

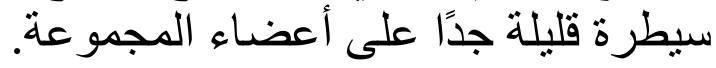

ـ المناخ المتحكم فيه: هو نوع مناخ غير شخصي ويركز على المهمة؛ حيث يتم توجيه سلوكيات

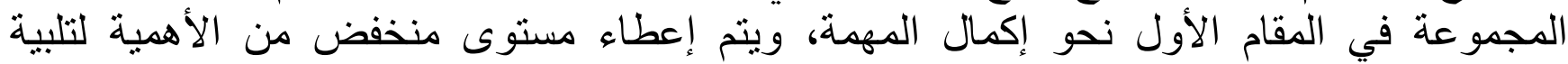
الاحتياجات الاجتماعية.

- مناخ مألوف: هو مناخ شخصي إلى حد كبير ولا لإوفر أي سيطرة. فالمنظمة تلبي الاحتياجات

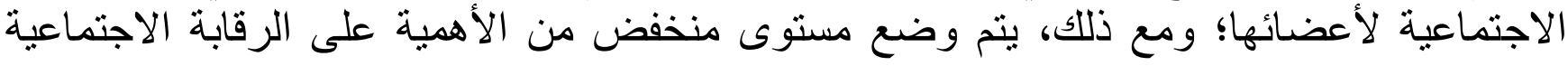
لإنجاز المهام.

ـ المناخ الأبوي: هو نوع من المناخ الذي لا يسمح فيه المدير للقائد بالخروج من المجموعة وحيث يتحمل المدير جميع المسؤوليات.

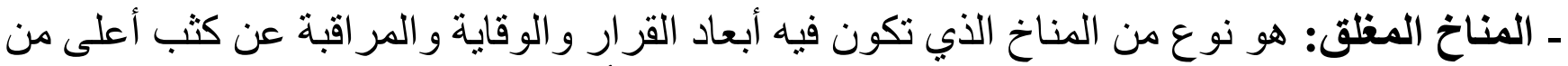

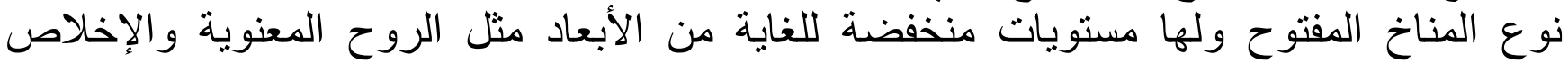
و الالنز ام و التفاهم (Karada, 2015 (124). المطلب الثاني: العوامل المؤثرة في المناخ التظظيمي هناك عدة عو امل تؤثر في المناخ التنظيمي ومن هذه العو امل ما يلي:

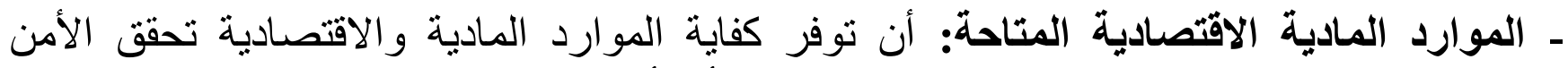

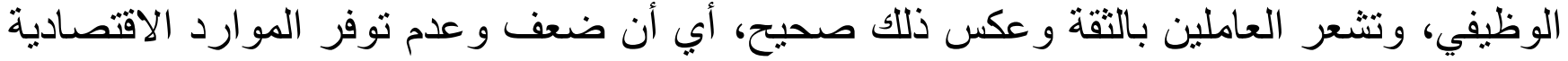

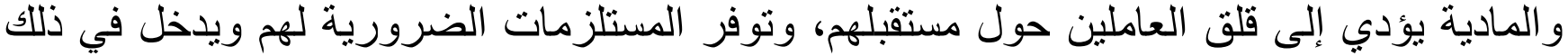

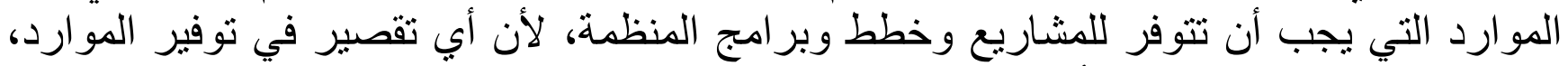

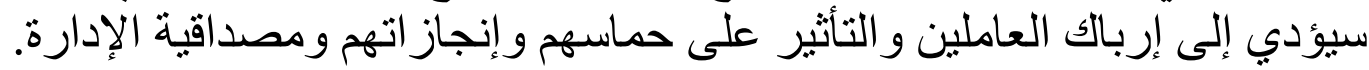

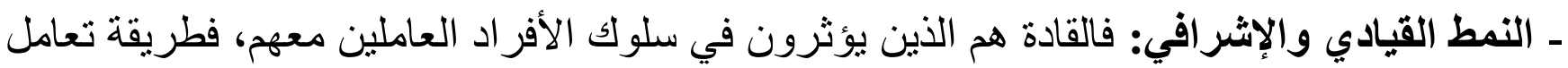

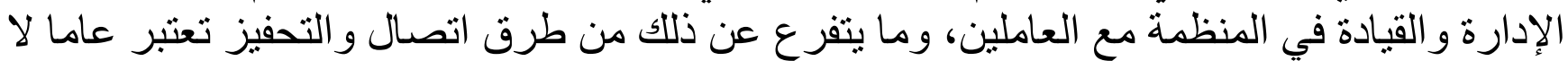

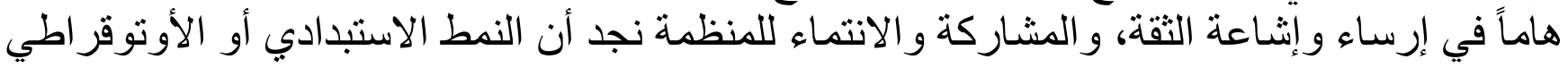

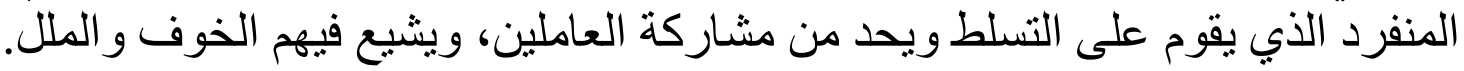

ـ السياسات الإدارية المحددة للاختيار والترقيات والأجور: و غير ها من الأمور المتعلقة بتنظيم علاقة

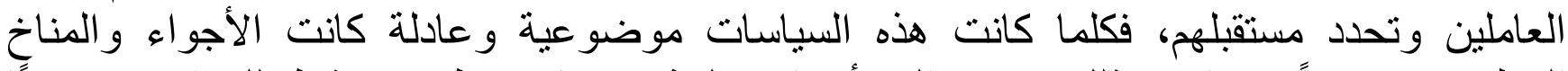
التنظيمي مشجعاً، و عكس ذللك يؤدي إلى أجواء سلبية، ومناخ تنظيمي مثبط للعز ائم ومضعفًا للمعنويات.

ـ القيم المهنية للإداريين والعاملين على مختلف مستوياتهم: بغض النظر عن مستوياتهم ومهنهم

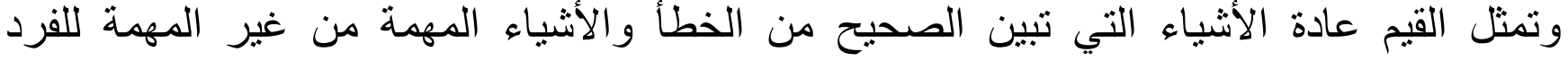
و المنظمة، وعادة ما يعتبر تعارض القيم مشكلة من المشاكل الرئيسية التي تو اجه المنظمة التئ، وتحول 
دون انسجام الأفر اد مع أهدافها وبيئتها، وبالتالي عجزها عن تحقيق أهدافها، و المنظمة التي تسود فيها

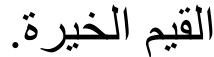

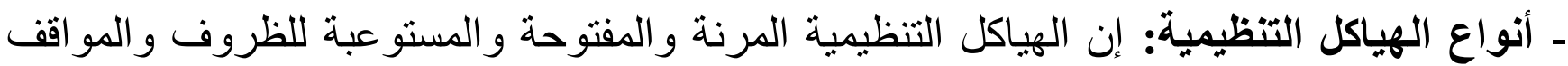

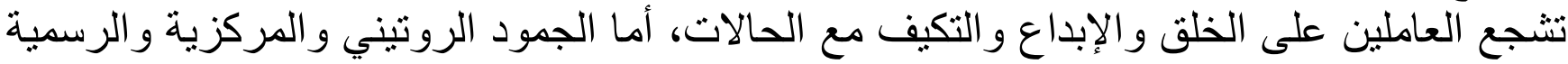

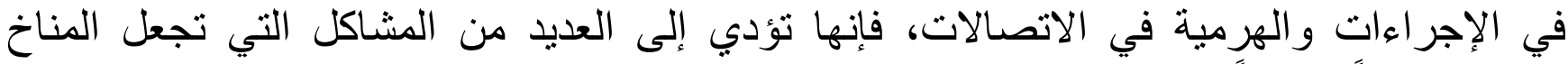
التنظيمي جافاً ومثبطاً.

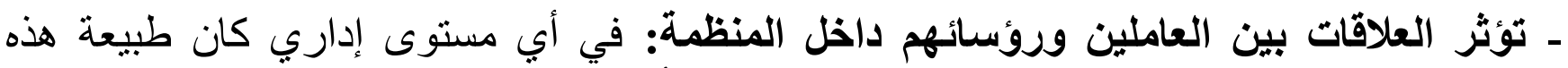

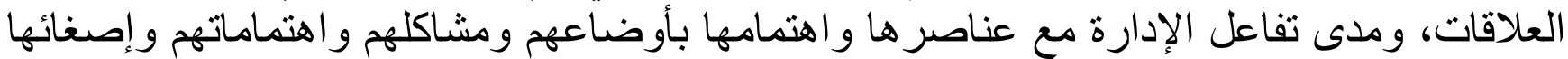

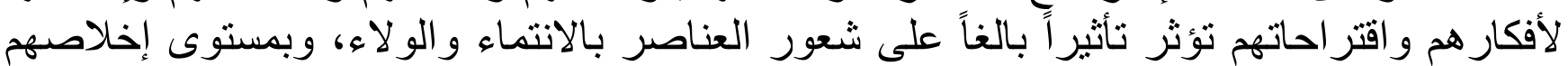

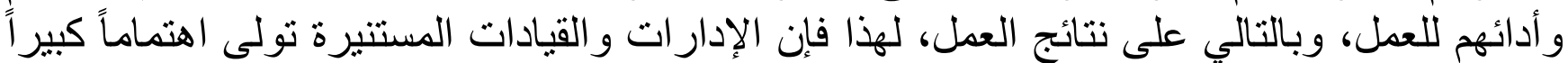
من الاهتمام والعناية بهذه العلاقات من خلال الاهتمام بالجوان بالإنسانية والاجتماعية للعاملين. (القاضي، 2015، 172-172).

المبحث الثالث: نماذج المناخ التنظيمي. هنالك عدة نماذج للمناخ التنظيمي وهي كالآتي:

\section{أ. نموذج لتون وسترينجر:}

يعهدف هذا النموذج إلى تقييم المناخ التنظيمي السائد في المنظمة و التعرف على ولى مدى انعكاسه أو تأثيره

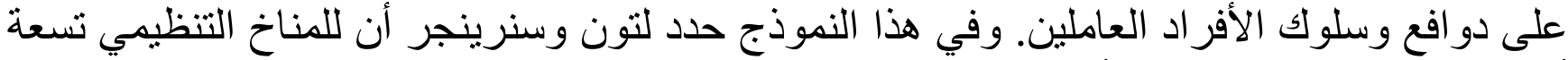

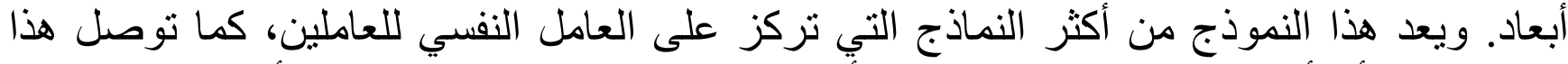

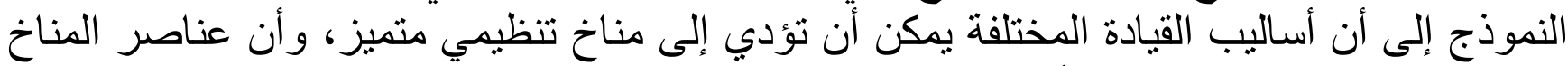

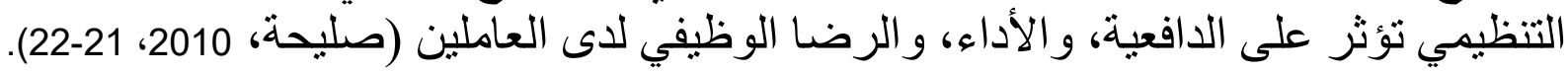

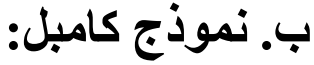

يعد هذا النموذج من الإسهامات الجادة التي قدمت في مجال تحديد أبعاد المناخ التنظيمي، وقد تم تحديد

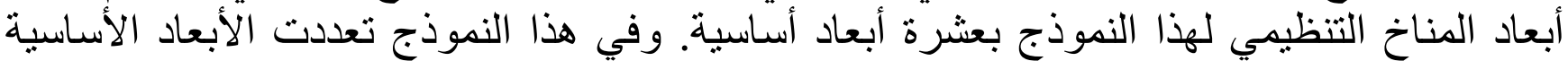

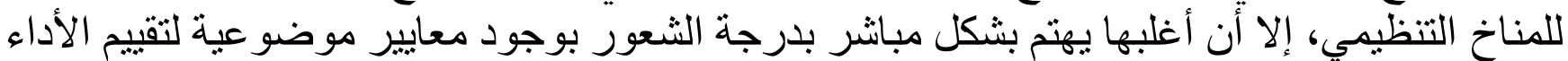

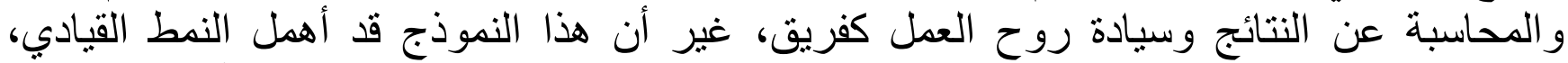

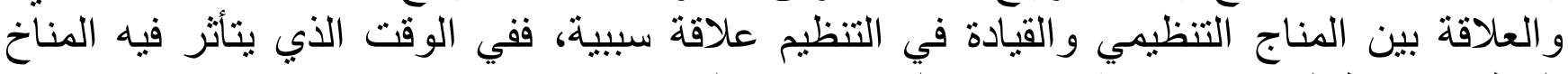

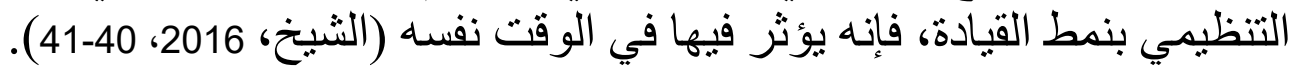

\section{ج. نموذج تيم وبيترسون:}

حدد تيم ويترسون في نموذجهما للمناخ التنظيمي، أن المناخ التنظيمي يتكون من ستة أبعاد هم:

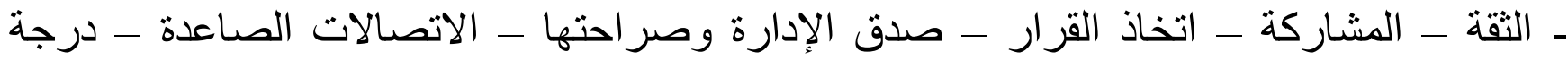

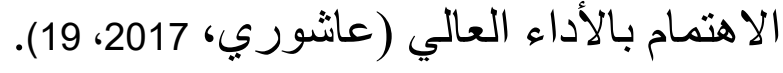




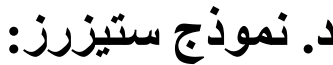

يتكون المناخ التنظيمي وفق نموذج سنتيزرز، من أربعة أبعاد رئيسة يمكن توضيحها وتوضيح ما

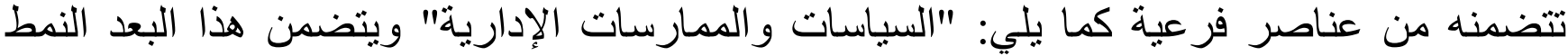

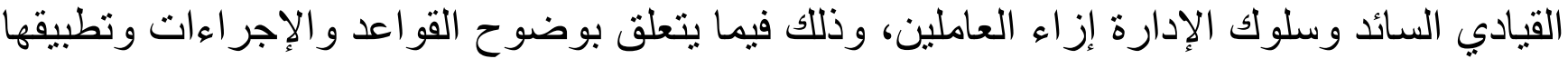

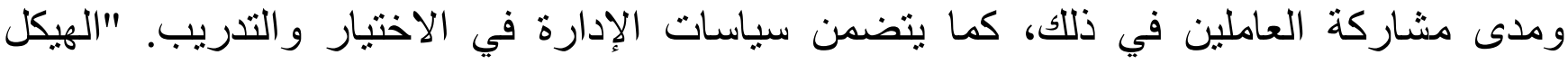
التنظيمي" ويتضمن هذا البعد درجة المركزية، نطاق الإشراف، حجم المنظمة، عدد المستويات

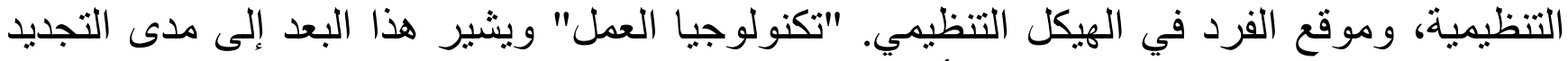

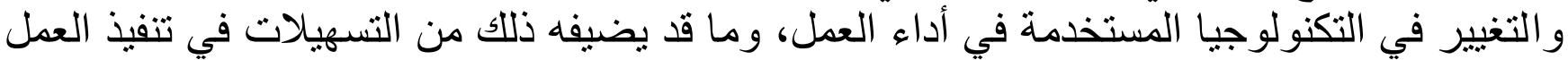
أو الإبداع فيه. " البيئة الخارجية" ويتضمن هذا البئية فئية البعد عناصر البيئة الخارجية المحيطة بالتنظيم و المؤثرة عليه، بما في ذلك العوامل الاقتصادية والعوامل السياسية، و العوامل الاجتماعية (الثيخ،

.) (42، 2016

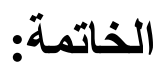

من خلال ما تم استعر اضه حول المناخ التظيمي وأثزه على المؤسسات الخاصة في سلطنة عمان

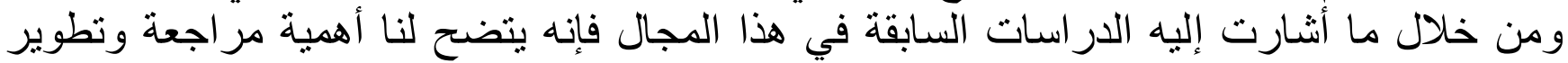

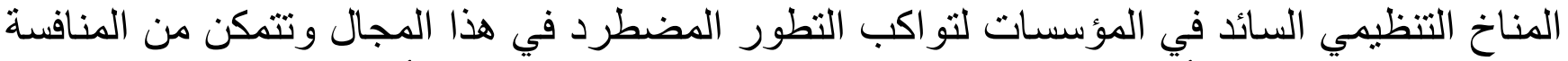

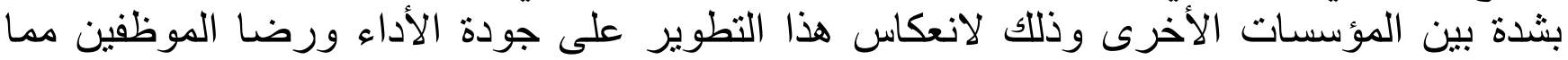

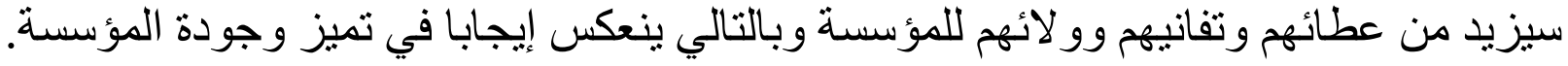

الحر احشة، حسين تحمه. (2011). إدارة الجودة الثاملة والأداء الوظيفي. عمان: دار جليس

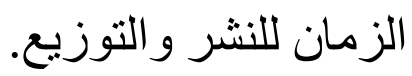

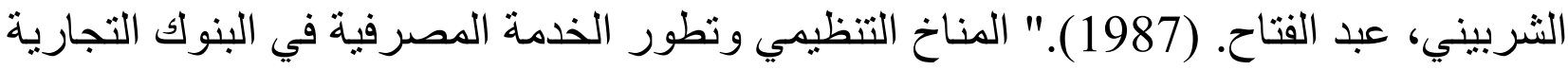

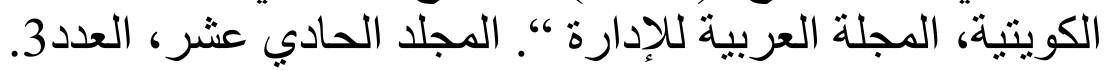

الثيخ، جلال محمود. (2016). المناخ التنظيمي وأثره على أداء الموظفين في وكالة الغوث

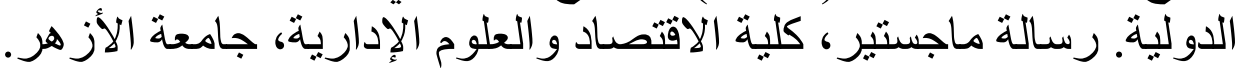

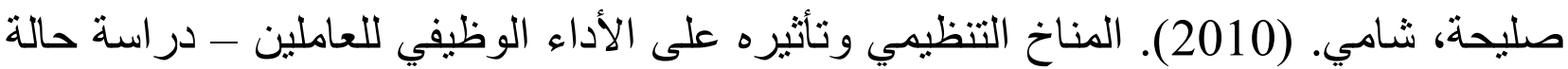

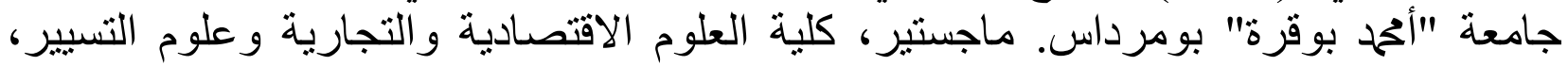
جامعة "أحمد بوقرة" بوة بورة بوداس.

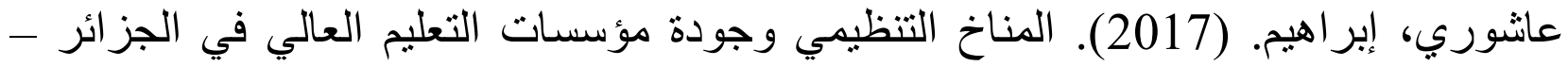

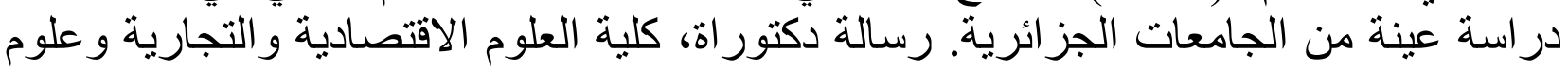
التسبير، جامعة حمح بوضياف المسيلة. 


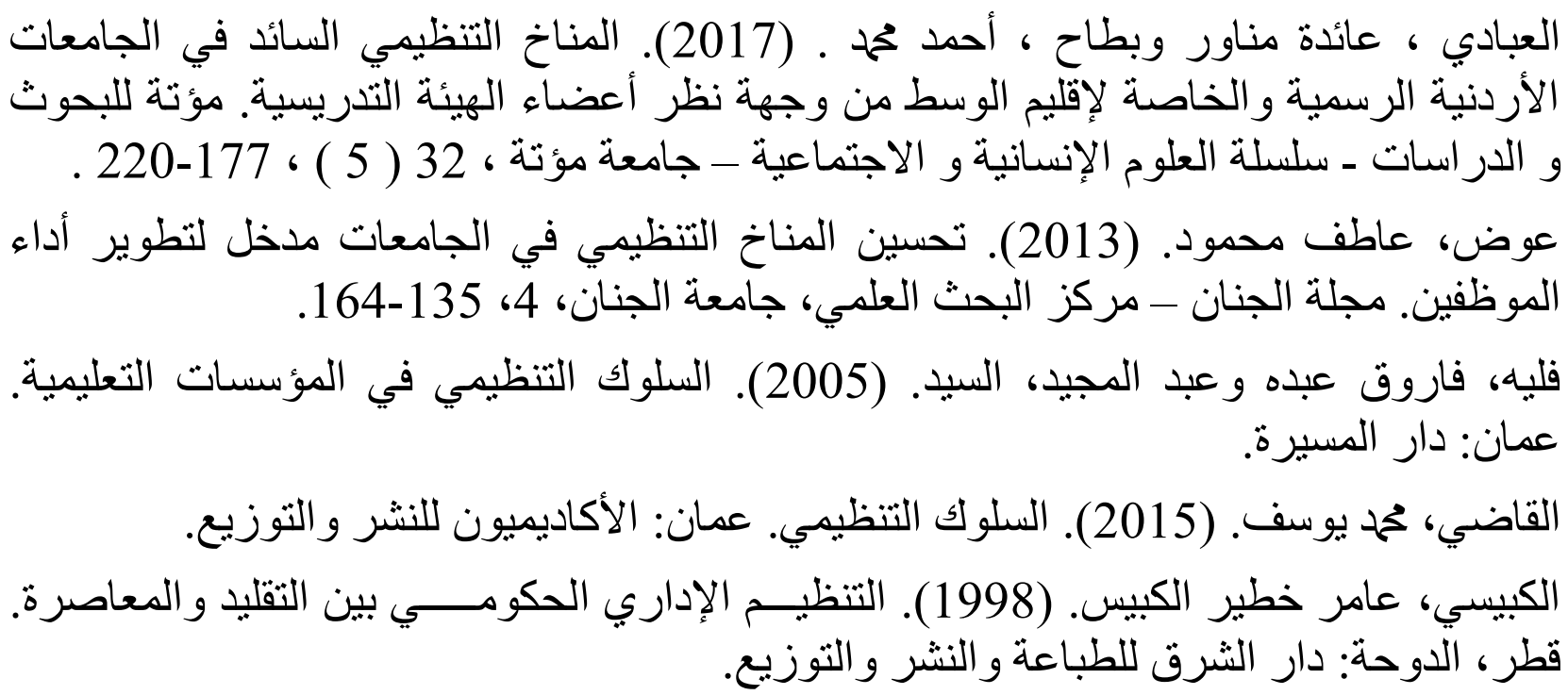

REFERENCES IN ROMAN ALPHABET

Alharahishat, Husayn Mahmd. (2011). 'lidarat Aljawdat Alshshamilat Wal'ada' Alwazifi. Eamana: Dar Julays Alzaman Lilnashr Waltawzie.

Alsharbini, Eabd Alfatah. (1987)." Almunakh Altanzimiu Watatawur Alkhidmat Almasrifiat fi Albunuk Altijariat Alkuaytiati, Almajalat Alearabiat Lil'iidara ". Almujalid Alhadi Eushra, Aledd3.

Alshiykhu, Jalal Mahmud. (2016). Almunakh Altanzimiu Wa'atharah Ealaa 'Ada' fi Wikalat Alghawth Aldawliat. Risalat Majstir, Kuliyat Alaiqtisad Waleulum Al'iidariati, Jamieat Al'azahr.

Salyhat, Shami. (2010). Almunakh Altanzimia Watathirah Ealaa Al'ada' Alwazifii Lileamilin - Dirasat Halat Jamiea "Amahmd Biwqir" Bumrdas. Majstir, Kuliyat Aleulum Alaiqtisadiat Waltijariat Waeulum Altasyiri, Jamiea "Amahamd Biwqira" Bumirdas.

Eashuri, 'librahim. (2017). Almunakh Altanzimia Wajawdat Muasasat Altaelim Alealii fi Aljazayir - Dirasat Eayinat Min Aljamieat Aljazayiriati. Risalat Dukturati, Kuliyat Aleulum Alaiqtisadiat Waltijariat Waeulum Altasyiri, Jamieatan Muhamad Bawdiaf Almasilat.

Aleabbadi , Eayidatan Munawir Wabitah , 'Ahmad Muhamad . (2017). Almunakh Altanzimia Alssayid fi Aljamieat Al'urduniyat Alrasmiat Walkhasat Li'iiqlim Alwasat Min Wijhat Nazar 'Aeda' Alhayyat Altadrisiati. Mawtatan Lilbihawth w Aldirasat - Silsilat Aleulum Al'iinsaniat w Alaijtimaeiat - Jamieatan Mutatan , 32 ( 5 ) , 177-220

Eawd, Eatif Mahmawud. (2013). Tahsin Almunakh Altanzimii fi Aljamieat Madkhal Litatwir 'Ada' Almuazafina. Majalat Aljnan - Markaz Albahth Aleilmii, Jamieat Aljanan, 4, 135-164.

Falayhi, Faruq Eabdah Waeabd Almajid, Alsayd. (2005). Alsuluk Altanzimiu fi Almuasasat Altaelimiati. Eamana: Dar Almasirat.

Alqadi, Muhamad Yusuf. (2015). Alsuluk Altanzimiu. Eamaana: Al'ukadimiuwn Lilnashr Waltawzie.

Alkabisi, Eamir Khatir Alkubays. (1998). Altnzym Al'iidariu Alhukumay Bayn Altaqlid Walmueasirat. Qutr, Aldwht: Dar Alshrq Liltabaeat Walnashr Waltawzie.

Al-Kurdi, O., El-Haddadeh, R \& Eldabi, T. (2020). The role of organizational climate in managing knowledge sharing among academics in higher education. International Journal of Information Management, 50, 217220.

Dargahi H, Musavi M, Shaham G. (2013). Organizational climate of hospitals at Tehran University of medical sciences. J Health Adm, 15 (50), 31-40. 